\title{
Sylys ${ }^{\circledast}$ surgical sealant: a safe adjunct to standard bowel anastomosis closure
}

\author{
Marguerite A W Stam ${ }^{1 *}$, Charlotte L J Mulder ${ }^{1}$, Esther C J Consten ${ }^{1}$, Jurriaan B Tuynman², \\ Christianne J Buskens ${ }^{3}$ and Willem A Bemelman ${ }^{3}$
}

\begin{abstract}
Background: Reducing the incidence of anastomotic leakages would benefit both patients and health care in general. Attempts to solve this problem have been disappointing thus far. Sylys ${ }^{\circledR}$ Surgical Sealant was developed as an extraluminal adjunct to standard closure techniques for bowel anastomosis procedures. We describe the results of a first-in-man study in which Sylys ${ }^{\circledR}$ Surgical Sealant is used. The aim of this study was to evaluate the safety of Sylys ${ }^{\circledast}$ Surgical Sealant in stoma reversal procedures.
\end{abstract}

Methods: This prospective, multicenter, non-randomized, first-in-man industry initiated study was performed in two independent hospitals in the Netherlands. The study population consisted of adults who were scheduled for an open ileostomy reversal procedure. Exclusion critera were: patients with severe co-morbidities, patients receiving antibiotics, immunosuppressive agents or steroids for pre-existing conditions. Follow up was conducted during 3 months after surgery at the outpatient clinic.

Results: Sixteen patients were eligible for inclusion. Twenty adverse events were recorded in 12 of the 16 treated patients (75\%). None of these events were considered to be related to Sylys ${ }^{\oplus}$ Surgical Sealant. No clinical signs of anastomotic leakage were reported.

Conclusions: In conclusion, this first-in-man application of Sylys ${ }^{\circledast}$ Surgical Sealant as an adjunct to standard bowel anastomosis closure techniques did not show any adverse effects in relation to the sealant in 16 patients.

Keywords: Sylys ${ }^{\circledast}$ surgical sealant, Anastomosis, Anastomotic leakage, lleostoma, Colorectal disease

\section{Background}

Colorectal surgery is associated with severe postoperative complications such as peritonitis, septic shock, multiple organ failure, and death. At least one third of the mortality after colorectal surgery is attributed to anastomotic leaks [1-5]. In a recent publication by the Dutch Surgical Colorectal Audit the incidence of anastomotic leakage after colon and rectum resections was 8.7\% [6]. Overall the reported leakage rates after colorectal surgery varies from $3 \%$ to $23 \%$ [1-5,7]. Anastomotic leakage leads to re-operations, admissions to intensive care units and an increased length of hospital stay $[8,9]$. The cost of treating a patient with an anastomotic leakage is on average five times higher [10].

\footnotetext{
* Correspondence: maw.stam@meandermc.nl

${ }^{1}$ Department of surgery, Meander Medical Centre, PO box 1502, 3800 BM Amersfoort, the Netherlands

Full list of author information is available at the end of the article
}

Reducing the percentage of anastomotic leakages would benefit both patients and health care in general. Attempts to solve this problem include, but are not limited to, staple line reinforcements, fibrin sealants, or collagen patches. However all with disappointing results [8,11-13].

Sylys ${ }^{\circ}$ Surgical Sealant was developed as an extraluminal adjunct to standard closure techniques for bowel anastomosis procedures. It is a synthetic pre-polymer with strong adherence to bowel tissue. The sealant is highly elastic and maintains strength during the natural healing of the anastomosis and then breaks down by hydrolysis into non-toxic components and is resorbed by the body within weeks.

We describe the results of a first-in-man study in which Sylys ${ }^{\oplus}$ Surgical Sealant is used. The aim of this study was to evaluate the safety of Sylys ${ }^{\oplus}$ Surgical Sealant in stoma reversal procedures. 


\section{Methods}

A prospective, multicenter, non-randomized, first-in-man industry initiated study was performed in two independent hospitals in the Netherlands; Meander Medical Centre in Amersfoort (a big teaching hospital) and Amsterdam Medical Centre in Amsterdam (tertiary referral center). Ethical approval was obtained by both medical ethical committees and the Dutch Health Care Inspectorate. Written consent was signed prior to inclusion.

\section{Patient population}

Eligible for inclusion were adults, scheduled for an open ileostomy reversal procedure between April and May 2013. Exclusion critera were: patients with severe comorbidities, an ASA classification over 2, patients receiving antibiotics for pre-existing condition or infection, steroids or immunosuppressive agents at the time of surgery. Follow up was conducted at the outpatient clinic during 3 months.

\section{Sylys ${ }^{\circledR}$ surgical sealant}

Sylys ${ }^{\oplus}$ Surgical Sealant (Cohera Medical Inc, Pittsburgh, USA) is a polyethylene glycol (PEG)-based synthetic prepolymer that utilizes silane chemistry in combination with urethane chemistry to produce a rapid curing, singlepart, moisture-cure sealant with strong adherence to bowel tissue. Preclinical use in mice did not show any safety risks (unpublished data).

\section{Procedures}

At least 1 hour prior to the first incision, Sylys ${ }^{\oplus}$ Surgical Sealant was taken from frozen storage $\left(-10^{\circ} \mathrm{C}\right.$ to $\left.-30^{\circ} \mathrm{C}\right)$ and allowed to thaw to room temperature. The surgical procedure was consistent with techniques used for standard open ileostomy takedown procedures. All surgeries were performed by experienced gastro-intestinal surgeons. The anastomotic junction was made using either staples, sutures or a combination of both. Upon conclusion of constructing the anastomotic junction Sylys ${ }^{\oplus}$ Surgical Sealant was applied circumferentially over the staple and/or suture line using the Sylys ${ }^{\oplus}$ applicator (Cohera Medical Inc, Pittsburgh, USA). Approximately five minutes was allowed to pass without disruption or manipulation of the anastomotic junction allowing Sylys ${ }^{\oplus}$ Surgical Sealant to cure. The sealant was rinsed with saline after 2 minutes to accelerate curing and keep the tissues moist.

\section{Study objectives}

Primary endpoint of this study was to determine the safety of Sylys ${ }^{\bullet}$ Surgical Sealant used during open ileostomy reversal procedures. Safety was measured in terms of complication rate and mortality during our follow-up period. Secondary endpoints of this study were length of hospital stay, reoperation rate, readmission rate, number/type of additional procedures due to complications and application time and convenience. For study purposes Adverse Events(AE) and Serious Adverse Events (SAE) were reported. According to protocol all deviations from the normal range had to be reported as $\mathrm{AE}$, despite recent surgery.

\section{Statistical analysis}

Numerical variables were displayed in terms of mean, standard deviation, median and number of observations. Categorical variables were displayed using number of observations and percentages. Subject disposition and safety analysis were conducted on the safety analysis set. All other analyses were conducted on the efficacy analysis set, unless specified otherwise.

\section{Results}

Sixteen patients were eligible for inclusion. Median age was 58.6 years (range 21.3-75.3). Median BMI $24.7 \mathrm{~kg} / \mathrm{m}^{2}$ (range 19.6-33.4). The majority of the enrolled patients was male $(\mathrm{n}=13 ; 81.3 \%)$. [Table 1] The initial reasons for ileostomy were surgery for: rectal cancer $(n=10)$, diverticulitis $(n=3)$, familial adenomatous polyposis $(n=2)$ and colitis $(n=1)$. Follow up was completed by all but one patient.

\section{Primary outcome: mortality and complication rate}

Twenty (20) adverse events were recorded in 12 of the 16 treated patients $(75 \%)$ over a three month period. Complications were subdivided in major complications (SAE) and minor complications (AE).

There were three major complications registered, all of which required hospitalization: diarrhoea as a consequence of chemotherapy resulting in dehydration $(n=1)$, ileus $(n=1)$ and deep tissue wound infection $(n=1)$. The latter two were interpreted as possibly device related. No clinical signs of anastomotic leakage were reported. There was no mortality in this group.

Minor complications are listed in Table 2. All minor events did not require (prolonged) hospitalization.

Table 1 Baseline characteristics

\begin{tabular}{lll}
\hline Characteristic & Mean (SD) & Median (range) \\
\hline Age (years) & $55.2(13.7)$ & $58.6(21,3-75.3)$ \\
Weight (kilogram) & $78.7(14.7)$ & $76.5(57.0-105.0)$ \\
Height (meter) & $1.78(0.09)$ & $1.78(1.64-1.97)$ \\
BMl (kg/m2) & $24.9(4.0)$ & $24.7(19.6-33.4)$ \\
Gender & & \\
Male & $13(81.3 \%)$ & \\
Female & $3(18.7 \%)$ & \\
\hline
\end{tabular}


Table 2 Complications after reversal ileostomy with Sylys ${ }^{\circledR}$ Surgical Sealant

\begin{tabular}{lll}
\hline Events & $\begin{array}{l}\text { Serious adverse } \\
\text { event (N) }\end{array}$ & $\begin{array}{l}\text { Adverse } \\
\text { event (N) }\end{array}$ \\
\hline Ileus & 1 & \\
Diarrhea by chemotherapy & 1 & \\
Deep tissue infection & 1 & 7 \\
Altered bowel habits & & 2 \\
Small intestine obstruction & 2 \\
Wound infection & 2 \\
Abdominal pain & 2 \\
Urologic disorders & 1 \\
Back pain & 1 \\
Gastroenteritis & 1 \\
Recurrent hepatic neoplasm & 1 \\
Nausea & 1 \\
Proctitis & \\
\hline
\end{tabular}

\section{Sylys ${ }^{\circledR}$ surgical sealant application procedure}

The mean duration of the surgical procedure was $52 \pm$ 12 minutes $(\mathrm{n}=15)$. Mean time to apply the Sylys Surgical Sealant was $34 \pm 24$ seconds $(\mathrm{n}=14)$. There was no need to remove or reapply Sylys ${ }^{\circ}$ Surgical Sealant in any of the 16 operated patients $(0 \%)$.

\section{Hospital stay}

Mean hospital stay length after the ileostomy reversal surgery + Sylys ${ }^{\circ}$ Surgical Sealant treatment was 3 days, with minimum and maximum of 2 and 5 days respectively.

\section{Reoperation and additional procedures}

None of the treated patients required additional surgical procedures or interventions.

\section{Discussion}

This safety-study did not show any adverse events related to the application of Sylys ${ }^{\circ}$ Surgical Sealant in a cohort of 16 patients having a ileostomy reversal procedure. Although numerous adverse events occurred, all could be attributed to the regular postoperative complications related to ileostomy reversal procedures. Kaidar-Person et al. reviewed 26 studies evaluating the complications of loop ileostomy closure. Reported rates of small bowel obstruction range from $0 \%$ to $15 \%$ and wound infections range from $0 \%$ to $18.3 \%$ [14]. These findings are in line with our results.

Three serious adverse events were reported. These were labeled serious, in line with international rules and regulations, because of the need for hospitalization. We considered the patient suffering from dehydration caused by diarrhoea after chemotherapy as not related to the application of the device. Two SAE's were labelled as possibly device related. One patient suffered from an ileus which resolved swiftly after oral laxatives. Additional tests could not clarify the cause of the obstruction, however it was possibly related to a bowel movement disorder caused by excessive use of piperidine derivates. The latter patient suffered from a deep tissue infection. A causative relationship between the two is unlikely, but cannot be excluded.

Furthermore, none of the 16 patients showed signs of allergic reactions towards Sylys ${ }^{\circ}$ Surgical Sealant, indicating that the polyethylene glycol (PEG)-based synthetic pre-polymer is well tolerated by the patients. Other known surgical sealants have reported increased inflammation and post-surgical adhesion formation. This is most likely due to the use of cyanoacrylate products. It has been reported that they might increase inflammatory reactions, cause anastomotic stricture and colonic obstruction, necrosis and severe adhesion formation $[13,15]$.

Applicability of the Sylys ${ }^{\circ}$ Surgical Sealant was a major point of interest for all participating surgeons since it potentially leads to added procedure time and therefore costs. Application of Sylys ${ }^{\circ}$ Surgical Sealant over the anastomotic junction required only 5 minutes of extra operating time: about 30 seconds to apply it, and 5 minutes for the pre-polymer to adhere to the intestinal tissue.

Our study had several limitations. Firstly the number of patients is fairly low. This was due to the nature of a safety study. Secondly the efficacy of the sealant could not be evaluated. To our knowledge none of the currently available coatings of intestinal anastomoses have shown convincing results [13]. Further studies are needed to evaluate the efficacy of Sylys ${ }^{\circledR}$ Surgical Sealant. Thirdly Sylys ${ }^{\circ}$ Surgical Sealant was tested in open procedures, since the open surgical setting allowed the surgeons to easily apply the sealant over the anastomosis. In the future, with the rise of laparascopic procedures, this product and its application kit will need to undergo minor modifications to be trocar-compatible after which it needs to be tested in a laparoscopic setting for its potential to reduce leakage of colorectal anastomosis.

Fourth, the applicability of the sealant was tested on an anastomosis where the sealant is simple to apply. Application on low anterior anastomosis is expected to be more troublesome.

\section{Conclusion}

In conclusion, this first-in-man application of Sylys ${ }^{\oplus}$ Surgical Sealant as an adjunct to standard bowel anastomosis closure techniques did not show any adverse effects in relation to the sealant in 16 patients. Larger trials have been scheduled to further investigate the efficacy of Sylys ${ }^{\circ}$ Surgical Sealant in reducing anastomotic leakage after laparascopic colorectal surgeries. 


\section{Competing interest}

The authors declare that they have no competing interest.

\section{Authors' contributions}

MS: Participated in the design of the study, the inclusion of patients, surgeries, performed the follow-up, performed data retrieval and wrote the manuscript. CM: Participated in the data retrieval and writing of the manuscript. EC: Participated in the design of the study, the inclusion of patients and performed the surgeries. JT: Participated in the inclusion of patients, performed the surgeries, the follow-up, and data retrieval. CB: Participated in the inclusion of patients, performed the surgeries, the follow-up, and data retrieval. WB: Participated in the design of the study, the inclusion of patients and performed the surgeries. All authors' read and approved the final manuscript.

\section{Acknowledgements}

Paul Verheijen and Werner Draaisma participated in the inclusion of patients. The development of the product and funding for this study and was provided by Cohera Medical, Inc.,209 Sandusky St., Pittsburgh, PA 15212, 412-231-1500.

\section{Author details}

'Department of surgery, Meander Medical Centre, PO box 1502, 3800 BM Amersfoort, the Netherlands. ${ }^{2}$ Department of surgery, VU Medical Centre, Amsterdam, Netherlands. ${ }^{3}$ Department of surgery, Academic Medical Centre, Amsterdam, Netherlands.

Received: 8 July 2014 Accepted: 20 August 2014

Published: 27 August 2014

\section{References}

1. Alberts JC, Parvaiz A, Moran BJ: Predicting risk and diminishing the consequences of anastomotic dehiscence following rectal resection. Colorectal Dis 2003, 5:478-482.

2. Walker KG, Bell SW, Rickard MJ, Meahanna D, Dent OF, Chapuis PH, Bokey EL: Anastomotic leakage is predictive of diminished survival after potentially curative resection for colorectal cancer. Ann Surg 2004, 240:255-259.

3. Güenaga KF, Matos D, Wille-Jørgensen P: Mechanical bowel preparation for elective colorectal surgery. Cochrane Database Syst Rev 2011, 9:CD001544.

4. Hyman N, Manchester TL, Osler T: Anastomotic leaks after intestinal anastomosis: it's later than you think. Ann Surg 2007, 245:254-258

5. Karanjia ND, Corder AP, Bearn P: Leakage from stapled low anastomosis after total mesorectal excision for carcinoma of the rectum. Br I Surg 1994, 81:1224-1226.

6. Daams F, Luyer M, Lange JF: Colorectal anastomotic leakage: aspects of prevention, detection and treatment. World J Gastroenterol 2013, 8(15):2293-2297.

7. Rullier E, Laurent C, Garrelon JL, Michel P, Saric J, Parneix M: Risk factors for anastomotic leakage after resection of rectal cancer. Br J Surg 1998, 85:355-358. PMID: 9529492.

8. Gaertner WB, Hagerman GF, Potter MJ: Experimental evaluation of a bovine pericardium-derived collagen matrix buttress in ileocolic and colon anastomoses. J Biomed Mater Res B Appl Biomater 2010, 92:48-54.

9. Kirchhoff P, Clavien PA, Hahnloser D: Complications in colorectal surgery: risk factors and preventive strategies. Patient Saf Surg 2010, 4:5.

10. Koperna T: Cost-effectiveness of defunctioning stomas in low anterior resections for rectal cancer: a call for benchmarking. Arch Surg 2003, 138(12):1334-1338. discussion 1339.

11. Cheragwandi A, Nieuwenhuis DH, Gagner M, Consten EC: An update of available innovative staple line reinforcement materials in colorectal surgery. Surg Technol Int 2008, 17:131-137.

12. Kolkert JL, Havenga K, ten Cate Hoedemaker HO, Zuidema J, Ploeg RJ: Protection of stapled colorectal anastomoses with a biodegradable device: the C-seal feasibility study. Am J Surg 2011, 201(6):754-758.

13. Pommergaard HC, Achiam MP, Rosenberg J: External coating of colonic anastomoses: a systematic review. Int J Colorectal Dis 2012, 27(10):1247-1258.
14. Kaidar-Person O, Person B, Wexner SD: Complications of construction and closure of temporary loop ileostomy. J Am Coll Surg 2005, 201(5):759-773

15. Portillo G, Franklin ME Jr: Clinical results using bioabsorbable staple-line reinforcement for circular stapler in colorectal surgery: a multicenter study. J Laparoendosc Adv Surg Tech A 2010, 20:323-327.

doi:10.1186/s13022-014-0006-6

Cite this article as: Stam et al: Sylys ${ }^{\oplus}$ surgical sealant: a safe adjunct to standard bowel anastomosis closure. Annals of Surgical Innovation and Research 2014 8:6.

\section{Submit your next manuscript to BioMed Central and take full advantage of:}

- Convenient online submission

- Thorough peer review

- No space constraints or color figure charges

- Immediate publication on acceptance

- Inclusion in PubMed, CAS, Scopus and Google Scholar

- Research which is freely available for redistribution

Submit your manuscript at www.biomedcentral.com/submit 